\title{
Research on Teaching Methods of Autonomous Learning in Mechanical Courses
}

\author{
Wang, Hongxia \\ College of Mechanical Engineering \\ Hubei Automotive Industries Institute \\ Shiyan, China \\ email:8784145@163.com
}

\author{
Liu, Qiang* \\ College of Mechanical Engineering \\ Hubei Automotive Industries Institute \\ Shiyan, China \\ email:168269057@qq.com \\ * Corresponding author
}

\begin{abstract}
With the increasing requirement of the society for the ability of the talents, the cultivation mode of the autonomous learning ability is crucial in improving the student's independence and innovation. Mechanical courses are the most importance basic courses of engineering colleges. As the rapid development of information technology, traditional teaching mode has lost the attraction for young college students. Therefore, an innovative change is desired in mechanical teaching area in the colleges to adapt to the trend of social development. This paper mainly aims to make a systematic study of multi-teaching methods and autonomous learning methods in mechanical courses. The research includes techniques and methods of teaching, teaching students in accordance with their aptitude, the reform of assessment methods, and other aspects. It's very important for satisfying the needs of individualized learning and facilitating efficient autonomous learning. Multi-teaching methods have been adopted in the experimental class. The results indicated that student's interest in learning mechanical courses and teaching quality has been improved, and the students showed a high degree of satisfaction with the course.
\end{abstract}

Keywords-mechanical courses; information technology; autonomous learning; teaching methods

\section{INTRODUCTION}

Mechanical courses are the most importance basic courses for the engineering colleges, which play an important role in cultivating student's engineering design ability. The course contents involve not only more theoretical knowledge, but also a lot of practical engineering design experience and methods. It is difficult for students to grasp the main points of knowledge using the traditional lecture form. From our teaching effect in recent years, failure rate in the exam is as high as $40 \%$ or so. For the students and teachers, the traditional teaching model is being shocked and challenged at the same time. Curriculum reform has been a major challenge for the teachers and colleges especially in the recent years. Therefore, there are many teachers for the teaching methods of the courses to have carried out a wide range of research work[1-5]. Based on the research results of other teachers and my experience in the teaching of mechanical basic courses for many years, the mechanical curriculum reform would be discussed from the following aspects, to improve the teaching quality. The ongoing reform of the high education system places high demands on the training of professionals and encourages the searching for new ways to improve the educational process in the university. Especially, the involvement of students is critical for effective classroom learning. The current curriculum reform in college education calls for the student's autonomous learning ability, which is also fitting in with the demand of the time. Therefore, to develop student's ability to learn actively rather than passively has been the focal point of teaching practice today. Some methods in mechanical courses are introduced specifically in this paper.

\section{INFORMATION TECHNOLOGY}

The rapid development of information technology has brought immeasurable reform prospects to the field of education. Information technology has become a focus of attention in the university education field. It would shape and accelerate the development of educational informatization. With the rapid popularity of intelligence mobile phone and tablet PC and other mobile terminals, information technology also powerfully supports the mobile learning, blended learning, autonomous learning and ubiquitous learning. Many informational instructional means such as MOOCs (Massive Open Online Course) , microlecture, micro-blog , QQ and micro-tas, etc. gradually meet the requirements of student's autonomous learning. MOOCs refers to the large-scale network open class, it has a large number of free high-quality curriculum resources. Microlecture refers to the informatization instruction design meticulously, in the form of streaming media showing around certain knowledge or teaching conducting short. MOOCs and microlecture are filmed and uploaded to the network platform. It is convenient for teachers to complete teaching activities that promote the learner's autonomous learning to get the best effect. The teachers and students can freely and timely communicate and interact with each other using micro-blog and mobile QQ platform. Micro tutor is classroom interaction tool based on WeChat. The teacher can ask the students to participate in the classroom teaching activities designed by themselves. Furthermore, the teacher can evaluate the teaching effect in real time using micro tutor. 


\section{A. MOOCs and Microlecture}

In order to apply the informational instructional means described above to mechanical courses successfully, construct new teaching and learning strategies and teaching model, we had recommended some high quality curriculum resources and MOOCs companys to students. It is an effective way to cultivate student's autonomous learning ability in the mechanical course. The microlecture is a short recorded audio or video presentation on a single, tightly defined topic[6]. It is another effective way to stimulate student's enthusiasm and guide the students to play subjective initiative. Making microlectures are the process of micro research. We should study the course content systematically and deeply, and find problems in the practical teaching, analyze problems, solve problems. Finally, we make the process into microlectures, simple and practical. The essence of course (including key points, important points, funny parts and error-prone part, etc) could be present in micro video. It would lead students into a knowledge hall, and make them study autonomously the course with depth and integrity. For example, the specific key points of mechanical courses (the mechanism degree of freedom calculation, force analysis of helical gear, calculation of gear ratio of planetary gear trains, stress analysis for the rolling bearing, etc.) have been made into microlectures. The microlectures were about 10-15 minutes long and effective video or audio, and support online play, they are easy to learn and understand. Students have downloaded one after another when the microlectures uploaded to the network platform. Though the microlecture above could be short, refined, powerful, academic, accessible ,but could catch student's eyes and inspire or motivate student's further learning, furthermore, it's worth watching again. The microlectures are suitable for students to learn by themselves because each microlecture is about one knowledge point or one single topic. Consequently, we would realize the promotion of college student's autonomous learning.

\section{B. Microblog and Mobile QQ platform}

MOOCs and microlecture lacked of timely communication between teachers and students. Teaching process is not only the process of imparting knowledge, but also the process of emotional communication[7]. Learning through MOOCs and microlecture individually always ignored the connection between teachers and students emotionally[8-10]. In order to overcome the problem of poor communication, we could freely and timely communicate with students via micro-blog and mobile QQ platform in the learning process, so as to enhance the emotional connection between teachers and students.

\section{Micro Tutor}

The above mentioned learning atmosphere cannot compare with learning in an actual class, more or less lower the efficiency of learning. It seems quite difficult to accelerate each other between teaching and learning[9]. The teaching system of micro tutor has been adopted to provide online questions, see question, view answer and classroom attendance services, etc in our class. Micro tutor has helped us to fully evaluate the learning process and the learning effect of the students, each student's participation in teaching activities is objectively recorded, data showed that who is the most active and most devoted students in the classroom. It can bring teachers "sense of control", bring students "sense of participation", and bring education managers "sense of security".

We admire deeply information technology to help students carry out autonomous, cooperative and inquiry learning focusing on teacher's role as a tutor and student's role as a partner in their knowledge internalization. However, MOOCs and microlecture lacked of integrity in knowledge transfer process. Each knowledge point could be only a individual micro unit. A whole learning system was cut into pieces. It is keeping pace with the fragments of learning but ruining systematization of learning. Students could make use of this micro contact to build knowledge framework on their own and teachers could develop their major.

\section{UNIT TEACHING}

Mechanical courses are basic course, there are more than ten teachers to the courses. Teacher plays a crucial role in the process of student's autonomous learning. Many innovative instructional methods have been developed to improve teaching efficiency, in which unit teaching was first used in the mechanical courses teaching. According to the professional characteristics of each teacher, one or two units of the course are chosen to teach all the students , thus, the teacher will have enough energy to make full preparation for the selected units, the quality of teaching will naturally be improved. All students enjoy a balanced teaching resources, moreover, teachers focus on teaching time, thus, the teachers would have more time to do teaching reform and research projects. Therefore, unit teaching is not only beneficial to resource optimization, but also conducive to the comprehensive development of teachers.

Confronted with the application of information technology in college education, what we emphasize is student-centered concept and embodying human being's key role.

\section{AutONOMY LECTURES}

In the traditional teaching mode, the main form is students listening to the teacher's lecture; students are in an extremely passive position during the whole process of higher education. This situation often leads to low learning efficiency. In order to attract student's interest to learn, culture student's study enthusiasm and initiative and improve mechanical courses teaching quality, we should change the traditional teaching mode; make students become the center of teaching. According to the professional characteristics of the students, some funny parts of mechanical courses, knowledge points which are not so important have been selected for student to teach themselves, our teachers in the classroom give appropriate guidance. The content of knowledge is not limited within the scope of a textbook. Therefore, it greatly expands the learning content. The data collected by the students was comprehensive and novel. Thus, their ability of collecting data, organizing class and solving problem will be developed in a considerable degree, so as to create stronger learning motivation. The result showed that involvement of students was critical for effective classroom learning. Autonomy lectures is useful to improve the student's interest in autonomous learning, it can achieve a 
multiplier effect. Students are very recognized in this way, the enthusiasm and love for the course has been greatly improved.

\section{EXAMINATION MODE}

The final exam scores are no longer the standard for student's ability to be fully considered. We pay more attention to the process evaluation system of students and the usual assessment efforts. In the assessment method, the usual assessment efforts is greatly increased, accounting for $50 \%$ of the final assessment. The usual evaluation include classroom tests, class discussion, literature searching and model making, etc. In the course of teaching, the main knowledge points such as drawing of kinematic sketch of mechanism concerning the eccentric piston pump have been tested in the class. Such approaches as case studies, hot issues discussion and other forms of knowledge, etc. could be used to enhance students understanding and enable them to grasp the key points as soon as possible. The data related to the machine at home and abroad was indexed and downloaded from the database(CNKI or EI etc.), so that the students can not only learn how to use the digital library, but also how to study the mechanical knowledge. According to the observation and analysis of common mechanisms and machines in daily life, let the students make physical model, which often induce student's innovative thinking. Some physical models were made by the students, as shown in Fig. 1.

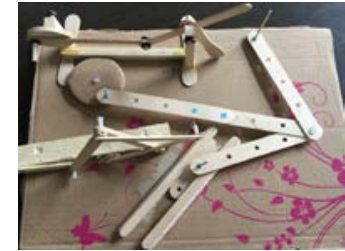

Fig. 1. Some physical models of students

The final examination scores accounted for $50 \%$ of the final assessment. The final examination paper is from the student and the teacher. The class is organized in groups of ten students in order to fulfill a set of examination paper cooperatively, which cultivated the spirit of team, cooperation and good interpersonal ability. The 50\% exam questions of the final examination paper are selected from the students. This can not only achieve the consolidation of knowledge but also improve greatly student's learning enthusiasm.

\section{TEST}

To validate the effect of mechanical curriculum reform, multi-teaching methods were applied in the experimental class, the traditional teaching method was adopted in the regular class. It took two years or so for investigating and visiting to decide whether the teaching methods can realize promotion of college student's autonomous learning. Several evaluation indexes (such as attendance, literature retrieval capability, listening rate, autonomous learning, and examination pass rate) were studied respectively. The test results of different courses in regular class and experimental class are shown in Table 1.

TABLE I. Test results

\begin{tabular}{|c|c|c|c|c|}
\hline Curriculum & \multicolumn{2}{|c|}{ Mechanical Principle } & \multicolumn{2}{|c|}{ Mechanical Designing } \\
\hline Class(Unit: person) & Regular class(420) & $\begin{array}{l}\text { Experimental } \\
\text { class }(120)\end{array}$ & $\begin{array}{c}\text { Regular class } \\
\text { (280) }\end{array}$ & $\begin{array}{c}\text { Experimental class } \\
\text { (40) }\end{array}$ \\
\hline attendance & $85 \%$ & $95 \%$ & $83 \%$ & $99 \%$ \\
\hline $\begin{array}{c}\text { Literature retrieval } \\
\text { capability }\end{array}$ & $25 \%$ & $100 \%$ & $30 \%$ & $100 \%$ \\
\hline listening rate & $60 \%$ & $92 \%$ & $65 \%$ & $98 \%$ \\
\hline autonomous learning & $30 \%$ & $90 \%$ & $35 \%$ & $93 \%$ \\
\hline examination pass rate & $69.4 \%$ & $91.6 \%$ & $75 \%$ & $95 \%$ \\
\hline
\end{tabular}

It is observed that autonomous learning ability in experimental class greatly improved, only about 3 over ten of the students tend to autonomous learning in the regular class. Other evaluating indicator including attendance, literature retrieval capability, listening rate and examination pass rate have improved to deferent degrees.

\section{CONCLUSION}

Modern society is a learning society, knowledge updated very quickly; the traditional teaching mode is difficult to meet the student's growing demand. It is shown that, with the help of information technology, the teaching quality of basic courses in mechanical speciality was greatly advanced. In consequence, fused multi-teaching methods discussed in this paper and traditional teaching mode complement each other. It is helpful to stimulate student's interest in actively learning the knowledge of professional machinery, and cultivate student's ability of learning and thinking.

\section{ACKNOWLEDGMENT}

This work was supported by the items of educational research of Hubei Automotive Industries Institute (JX201618); the Foundation of Hubei Ministry of Education (B2016089) the Doctoral Science Foundation, Hubei Automotive Industries Institute (No.BK201406). 


\section{REFERENCES}

[1] Gumarova Sh. Zhubanova K. Issabaeyva B. The modern educational technology in professional competence enhancement of future specialists, International Journal of Applied Engineering Research. 2016,11(5): 3038-3041.

[2] D.H. Baydrahmanov, Pedagogical conditions of formation of cognitive activity of students through computer technology in teaching foreign language: Dis. Cand. ped. Sciences. Astana p. 12, 2010.

[3] LI Bin, JIAN Yu-qing,PENG Cai-yun. Unite Multi-Teaching Methods and Independent Studies Improve Pharmaceutical English Teaching Quality, Education teaching forum.2017, 2:164-165. (In Chinese)

[4] Zhang Hao and Hong qiong. The status quo survey and analysis of college students autonomous learning under the u-learning environment, Logistics Sci-Tech.2017,2: 152-154. (In Chinese)
[5] Wang Hongxia and Fengxia. Discussion on teaching method of mechanical design basic course, Journal of exam week. 2014,60:155156.(In Chinese)

[6] Liu Xiaohong and Wang Lisi. The Analysis on Systematic Development of College Microlecture. Higher Education Studies, 2013, 3(6):65-70.

[7] You, Y. A Brief Analysis on the Integration of Micro Teaching and Traditional Teaching. Informatization Construction, 2015, No. 6, 191.

[8] K. F. Hew and W. S. Cheung. Students' and Instructors' Use of Massive Open Online Courses (MOOCs): Motivations and Challenges [J]. Educational Research Review,2014,(12):47.

[9] Song Yang. The Application of Microlecture in College English Teaching Process in China, Open Access Library Journal, 2016, 3:1-6.

[10] Xu,C.F. and Guo, Q. The Theory of Micro Lessons and Effective Integration of Traditional Teaching. Career Horizon, 2014, No. 1, 74-76. 